\title{
Yarn dyed wastewater treatment using hybrid electrocoagulation- Fenton method in a continuous system: Technical and economical viewpoint
}

\author{
Denny Gunawan, Vincensius Billy Kuswadi, Lanny Sapei, Lieke Riadi ${ }^{\dagger}$ \\ Department of Chemical Engineering, Universitas Surabaya, Jl. Raya Kalirungkut, Surabaya 60293, Indonesia
}

\begin{abstract}
Yarn dyed wastewater has to be treated prior to disposal into the water bodies due to its high content of harmful organic compounds. In this study, the performance of Chemical Oxygen Demand (COD) removal and kinetic rate constant are investigated via hybrid electrocoagulation-Fenton in a continuous system using wastewater discharged from a yarn dyed industry in Surabaya city. The wastewater was treated in a batch mode using electrocoagulation to reduce Total Suspended Solid, followed by Fenton method in a continuous system to reduce COD level. Various $\mathrm{Fe}(\mathrm{II})$ feeding modes, molar ratio of $\mathrm{Fe}(\mathrm{II}) / \mathrm{H}_{2} \mathrm{O}_{2}$, initial $\mathrm{pH}$ of wastewater, and flow rate are used in this study. The results show that $\mathrm{COD}$ removal process obeys a pseudo-first order kinetics. At $\mathrm{Fe}(\mathrm{II}) / \mathrm{H}_{2} \mathrm{O}_{2}$ ratio of $1: 10$, initial wastewater $\mathrm{pH}$ of 3.0 , and feed flow rate of $30 \mathrm{~mL} / \mathrm{min}$, the COD removal efficiency was observed to be $80 \%$, and the kinetic rate constant is $0.07046 \mathrm{~min}^{-1}$. The chemical cost for the treatment estimated to be IDR 160 per L wastewater, which is cheaper than the previously reported batch system of IDR $256 / \mathrm{L}$.
\end{abstract}

Keywords: COD, Continuous system, Electrocoagulation, Fenton, Yarn dyed wastewater

\section{Introduction}

Yarn dyed wastewater is classified as a hazardous waste due to its high content of non-biodegradable organic dye molecules. Those molecules, mostly azo dyes are harmful to living organisms owing to its toxicity, carcinogenicity, and mutagenicity [1]. As wastewater discharge from a yarn dyeing industry located in Surabaya does not meet the regulatory limits, therefore the wastewater has to be treated prior to disposal. The suitable method has to be designed in order to effectively treat the wastewater according to its inherent characteristics. The conventional biological method cannot effectively treat this type of wastewater due to a great extent of non-biodegradable organic compounds which is very difficult to be digested by the microbes [2].

Advanced oxidation processes (AOPs), which involve the generation of hydroxyl radicals $\left(\mathrm{HO}^{\circ}\right)$ as the oxidation agent have the potential to decompose these non-biodegradable organic substances and enhance the biodegradability of textile wastewater. Recently, numerous literatures have reported textile wastewater treatments by using AOPs such as ozonation [3], photo-Fenton

This is an Open Access article distributed under the terms of the Creative Commons Attribution Non-Commercial License (http://creativecommons.org/licenses/by-nc/3.0/) which permits unrestricted non-commercial use, distribution, and reproduction in any medium, provided the original work is properly cited.

Copyright (C) 2018 Korean Society of Environmental Engineers process [4], and Fenton process [5]. Among these AOPs, Fenton process is considered attractive since it offers many advantages, such as high performance, simplicity, and non-toxicity [6]. However, Fenton process is less effective for wastewater at high Total Suspended Solid (TSS) condition. Therefore, a hybrid electrocoagulation-Fenton system is proposed in this research. Electrocoagulation process is first conducted to reduce TSS level, which is then followed by Fenton process to reduce the Chemical Oxygen Demand (COD) level [7]. In Fenton process, hydrogen peroxide was catalyzed by ferrous ions to generate hydroxyl radicals $\left(\mathrm{HO}^{\bullet}\right)$ according to Eq. (1) [8].

$$
\mathrm{H}_{2} \mathrm{O}_{2}+\mathrm{Fe}^{2+} \rightleftharpoons \mathrm{Fe}^{3+}+\mathrm{OH}^{-}+\mathrm{HO}^{\bullet}
$$

Hydroxyl radical $\left(\mathrm{HO}^{\bullet}\right)$ is responsible to attack organic dye molecules $(\mathrm{RH})$ in textile wastewater producing radical organic compound $\left(\mathrm{R}^{\bullet}\right)$ as indicated in Eq. (2) [8].

$$
\mathrm{RH}+\mathrm{HO}^{\bullet} \rightarrow \mathrm{R}^{\bullet}+\mathrm{H}_{2} \mathrm{O}
$$

The radical organic compound $\left(\mathrm{R}^{\bullet}\right)$ and hydroxyl radical (HO^)

\footnotetext{
${ }^{\dagger}$ Corresponding author

Email: lieke@staff.ubaya.ac.id

Tel: +62-312981158 Fax: +62-312981387

ORCID: 0000-0003-4028-387X
}

Received August 17, 2017 Accepted October 15, 2017 
can further degrade organic dye molecule ( $\mathrm{RH}$ ) into carbon dioxide and water. In Fenton oxidation cycle, ferrous ions can be regenerated from ferric ions reduction by the presence of hydrogen peroxide according to Eq. (3) and (4) [8].

$$
\begin{gathered}
\mathrm{Fe}^{3+}+\mathrm{H}_{2} \mathrm{O}_{2} \rightarrow \mathrm{Fe}^{2+}+\mathrm{H}^{+}+\mathrm{HO}_{2}^{\bullet} \\
\mathrm{Fe}^{3+}+\mathrm{HO}_{2}^{\bullet} \rightarrow \mathrm{O}_{2}+\mathrm{Fe}^{2+}+\mathrm{H}^{+}
\end{gathered}
$$

Hybrid electrocoagulation-Fenton in a batch system has been demonstrated to be a reliable process for textile wastewater treatments [7]. For large scale application, a batch system is not recommended because of its high labor cost. Therefore, hybrid electrocoagulation-Fenton in a continuous mode is more attractive from both technical and economical viewpoints. The aims of this research are to determine COD removal efficiency and rate constants in the continuous Fenton process at various Fe(II) feeding modes, molar ratios of $\mathrm{Fe}(\mathrm{II}) / \mathrm{H}_{2} \mathrm{O}_{2}$, initial $\mathrm{pH}$ of wastewater, and flow rate. The results are compared to those in a batch system which was previously studied [7]. A previous work which has been carried in a batch system showed the rate constant of 0.0053 $\min ^{-1}$ [7]. Other studies using Fenton process to treat coking, bleaching, and olive mill wastewater were carried out in a batch system and has demonstrated good COD removal efficiency [8-10]. The operational cost of hybrid electrocoagulation-Fenton method in continuous system was also estimated in this study.

\section{Experimental Section}

Wastewater was collected from a yarn dyed industry which was located in Surabaya, Indonesia. The experimental set up is shown in Fig. 1. The electrocoagulation process was carried out in a $120 \times 120 \times 100 \mathrm{~mm}^{3}$ flexi glass reactor with $\mathrm{Al} / \mathrm{Al}$ rectangular plate ( $8 \mathrm{~cm}$ by $8 \mathrm{~cm}$ with $2 \mathrm{~mm}$ of thickness) as anode and cathode [11]. Post electrocoagulation, the Fenton process was carried out in a $1 \mathrm{~L}$ glass Continuous Stirred Tank Reactor (CSTR) equipped with a stirrer. The characteristic of wastewater can be seen in Table 1. A known volume of $2 \mathrm{M}$ of hydrochloric acid solution was added to the wastewater to adjust the initial $\mathrm{pH}$. Fe(II) was fed into the CSTR under two different feeding modes. The first feeding mode (A) was carried out by dissolving ferrous sulphate heptahydrate in the reactor which contained $1 \mathrm{~L}$ of wastewater while the other feeding mode (B) was carried out by dissolving ferrous sulphate heptahydrate in the electrocoagulation effluent vessel and also in the reactor which has already contained the wastewater. The Fenton process was carried out with the mixing speed of $350 \mathrm{rpm}$ at room temperature $\left(25^{\circ} \mathrm{C}\right)$. Three peristaltic pumps were used in the CSTR systems to maintain the continuous flow. Wastewater-iron solution and 30\% hydrogen peroxide solution were separately fed into the reactor. The flow rates of wastewater-iron solution were varied while the flow rates of hydrogen peroxide were calculated based on optimum hydrogen peroxide dosage [9], which were $8 \mathrm{~mL} / \mathrm{h}, 15 \mathrm{~mL} / \mathrm{h}$ and $22 \mathrm{~mL} / \mathrm{h}$. The parameters used for the study were molar ratio of $\mathrm{Fe}(\mathrm{II}) / \mathrm{H}_{2} \mathrm{O}_{2}$ (1:4.5 and 1:10), initial $\mathrm{pH}$ of wastewater (3.0 and 5.0), and wastewater flow
Table 1. The Characteristic of Wastewater before and after Electrocoagulation

\begin{tabular}{cccc}
\hline Parameters & $\begin{array}{c}\text { Before } \\
\text { electrocoag- } \\
\text { ulation }\end{array}$ & $\begin{array}{c}\text { After } \\
\text { electrocoag- } \\
\text { ulation }\end{array}$ & $\begin{array}{c}\text { Removal } \\
\text { efficiency }\end{array}$ \\
\hline COD & $829 \mathrm{ppm}$ & $312 \mathrm{ppm}$ & $62.4 \%$ \\
TSS & $11,660 \mathrm{ppm}$ & $2,650 \mathrm{ppm}$ & $77.3 \%$ \\
$\begin{array}{c}\text { Color } \\
\text { (Optical Density) }\end{array}$ & 1.335 & 0.029 & $97.8 \%$ \\
pH & 10.59 & 6.8 & $\mathrm{~N} / \mathrm{A}$ \\
\hline
\end{tabular}

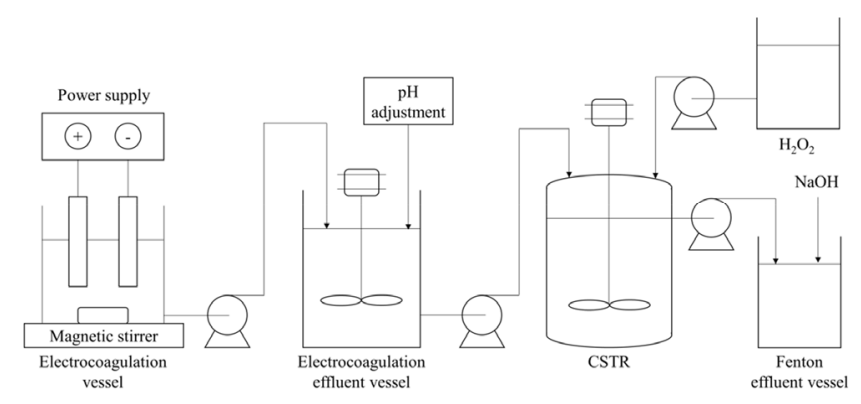

Fig. 1. Experimental set-up.

rate $(30 \mathrm{~mL} / \mathrm{min} ; 60 \mathrm{~mL} / \mathrm{min}$ and $90 \mathrm{~mL} / \mathrm{min})$. Samples were taken periodically up to $120 \mathrm{~min}$ of experiment.

COD was measured using a closed reflux and colorimetric method. TSS was analyzed using the dried method. All assays were carried out based on APHA method [12]. Color measurement was recorded from 200 to $800 \mathrm{~nm}$ wavelengths using a UV-Vis spectrophotometer and the absorbance values at $629 \mathrm{~nm}$ (as optical density) was evaluated before and after treatment [13].

\section{Results and Discussion}

The characteristics of wastewater prior and after the electrocoagulation process are presented in Table 1, which clearly shows the effectiveness of electrocoagulation process to reduce the TSS, COD and color. The removal efficiencies are calculated to be $77.3 \%, 62.4 \%$, and $97.8 \%$ for TSS, COD and color, respectively. The effect of Fenton process on COD removal is described in the subsequent section.

\subsection{Effect of Fe(II) Feeding Mode}

The effect of $\mathrm{Fe}(\mathrm{II})$ feeding modes is depicted in Fig. 2 which shows that feeding mode $\mathrm{B}$ gives higher COD removal efficiencies. The experiment condition was set at 1:4.5 molar ratio of $\mathrm{Fe}(\mathrm{II})$ to $\mathrm{H}_{2} \mathrm{O}_{2}$, initial $\mathrm{pH}$ of 3.0 and wastewater flow rate of $30 \mathrm{~mL} / \mathrm{min}$.

The presence of $\mathrm{Fe}(\mathrm{II})$ both inside the reactor and in feed tank could react directly with hydrogen peroxide, which was fed continuously into the CSTR, thus producing more hydroxyl radicals. The presence of $\mathrm{Fe}(\mathrm{II})$ in feeding tank which was continuously fed into the reactor would also maintain the Fenton process as hydrogen peroxide was also continuously fed to the reactor. By contrast, Fe(II) catalyst which is only fed to the reactor at initial 


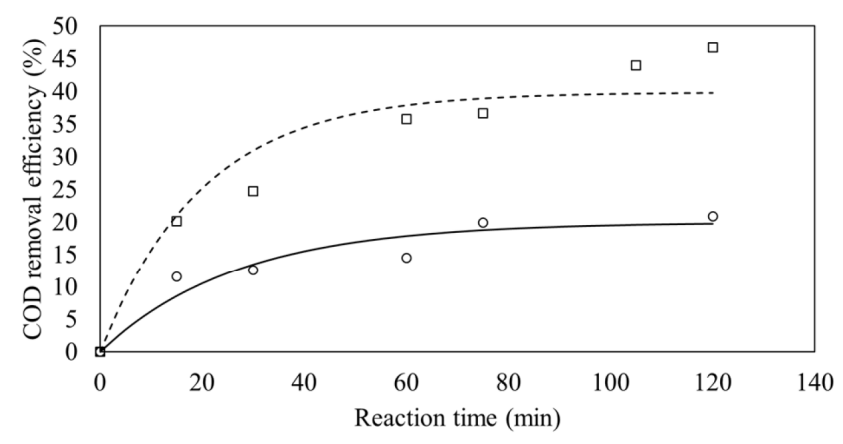

— Feeding mode A (model) --- Feeding mode B (model)

- Feeding mode A (experiment) $\square$ Feeding mode B (experiment)

Fig. 2. COD removal efficiencies at various Fe(II) feeding mode vs. reaction time.

Table 2. Pseudo-first Order Rate Constants at Different Fe(II) Feeding Modes

\begin{tabular}{ccc}
\hline Feeding mode & $\mathbf{k}^{\prime}\left(\mathbf{m i n}^{-1}\right)$ & $\mathbf{R}^{2}$ \\
\hline A & 0.00749 & 0.9167 \\
B & 0.01991 & 0.9263 \\
\hline
\end{tabular}

phase may lead to catalyst washout. The lack of Fe(II) catalyst in the reactor led to less generation of hydroxyl radicals since Fe(II) plays a crucial role to generate hydroxyl radicals from hydrogen peroxide.

The concentration of COD is plotted against time to elucidate the kinetic of the organic degradation. Previous study show the degradation kinetic obeys pseudo-first order [14]. By assuming the hydroxyl radical is excess, the equation of reaction rate as followed.

$$
-r=k C_{H O \bullet} C=k^{\prime} C
$$

where $C$ is the concentration of organic substances express as $\mathrm{COD}, C_{\mathrm{HO}}$ is the concentration of hydroxyl radicals, $k$ is the second order rate constant, and $k^{\prime}$ is the pseudo-first order rate constant. The start-up CSTR model for pseudo-first order kinetics can be expressed by Eq. (6) [14].

$$
\frac{c_{0}-c}{c_{0}}=\frac{\tau k^{\prime}}{1+\tau k^{\prime}}\left(1-\exp \left(-\left(k^{\prime}+\frac{1}{\tau}\right) t\right)\right)
$$

where $\tau$ is space time (reactor volume divided by wastewater flow rate).

The pseudo first-order rate constants are determined based on the data of COD removal efficiency versus time using Matlab and found to be $0.00749 \mathrm{~min}^{-1}$ and $0.01991 \mathrm{~min}^{-1}$ for feeding mode A and B, respectively, as is presented in Table 2. It is clear that the removal efficiency is higher under feeding mode $\mathrm{B}$ due to higher hydroxyl radicals generation than feeding mode A.

\subsection{Effect of Fe(III)/ $\mathrm{H}_{2} \mathrm{O}_{2}$ Molar Ratio in the Feed Stream}

The ratio of ferrous ions to hydrogen peroxide is very crucial for Fenton process. To investigate the effect of $\mathrm{Fe}(\mathrm{II}) / \mathrm{H}_{2} \mathrm{O}_{2}$ molar ratio in feeding stream, two different $\mathrm{Fe}(\mathrm{II}) / \mathrm{H}_{2} \mathrm{O}_{2}$ molar ratios were tested. The hydrogen peroxide dosage was held constant

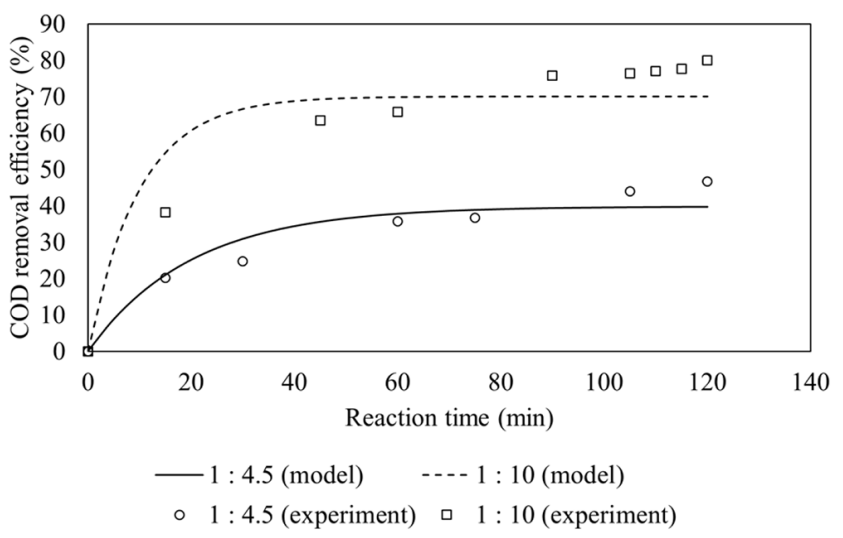

Fig. 3. Profile of $\mathrm{COD}$ removal at various $\mathrm{Fe}(\mathrm{II}): \mathrm{H}_{2} \mathrm{O}_{2}$ molar ratios.

Table 3. Pseudo-first Order Rate Constants at Different Fe(II)/ $/ \mathrm{H}_{2} \mathrm{O}_{2}$ Molar Ratios

\begin{tabular}{ccc}
\hline $\mathbf{F e}(\mathrm{II}) / \mathbf{H}_{2} \mathbf{O}_{2}$ & $\mathbf{k}^{\prime}\left(\mathbf{m i n}^{-1}\right)$ & $\mathbf{R}^{2}$ \\
$1: 4.5$ & 0.01991 & 0.9263 \\
$1: 10$ & 0.07046 & 0.8946 \\
\hline
\end{tabular}

(four times initial COD concentration) while $\mathrm{Fe}(\mathrm{II}) / \mathrm{H}_{2} \mathrm{O}_{2}$ molar ratio changed from 1:4.5 to 1:10. The initial $\mathrm{pH}$ and flow rate of wastewater were kept at 3.0 and $30 \mathrm{~mL} / \mathrm{min}$, respectively.

Fig. 3 shows that the effect of $\mathrm{Fe}(\mathrm{II}) / \mathrm{H}_{2} \mathrm{O}_{2}$ molar ratio on COD removal. Higher removal COD efficiency is observed at 1:10 molar ratio. This is because more Fe(II) is present at 1:4.5 molar ratio than 1:10, leading to more hydroxyl radical scavenging reaction as indicated in Eq. (7) [15].

$$
\mathrm{OH}^{\bullet}+\mathrm{Fe}^{2+} \rightarrow \mathrm{Fe}^{3+}+\mathrm{OH}^{-}
$$

The scavenging reaction results in reduced hydroxyl radical concentration, thus decreasing its ability for the COD removal. The lower hydroxyl radical concentration at molar ratio of 1:4.5 was also confirmed by CSTR model, similar to that on Fe(II) in feeding mode A.

The pseudo-first order rate constants at $\mathrm{Fe}(\mathrm{II}) / \mathrm{H}_{2} \mathrm{O}_{2}$ molar ratio of 1:4.5 and 1:10 are calculated to be $0.01991 \mathrm{~min}^{-1}$ and 0.07046 $\mathrm{min}^{-1}$, respectively as shown in Table 3 . The rate constants for both ratio of $\mathrm{Fe}(\mathrm{II}) / \mathrm{H}_{2} \mathrm{O}_{2}$ are different since less hydroxyl radical were produced for the molar ratio of $\mathrm{Fe}(\mathrm{II}) / \mathrm{H}_{2} \mathrm{O}_{2}$ of $1: 4.5$.

The COD removal efficiency in a continuous system at molar ratio of 1:10 is higher than the batch system which used molar ratio of $1: 15$ (80\% vs $70 \%$ ) [10]. However, the COD removal efficiency in a batch system which used molar ratio of 1:10 was 83.7\% [10], it proved that the best molar ratio of $\mathrm{Fe}(\mathrm{II}) / \mathrm{H}_{2} \mathrm{O}_{2}$ was 1:10 both in batch and continuous systems.

\subsection{Effect of Wastewater Initial pH}

Fenton process was a highly $\mathrm{pH}$ dependent process because $\mathrm{pH}$ affected the hydroxyl radical generation in the Fenton reaction. Fig. 4 shows the effect of wastewater initial $\mathrm{pH}$ on COD removal. 


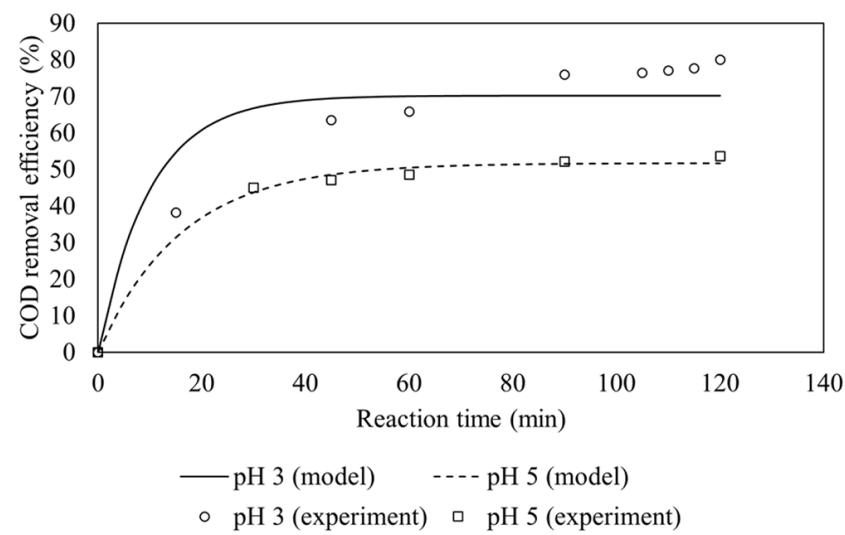

Fig. 4. COD removal efficiencies at various initial $\mathrm{pH}$ values vs. reaction time.

Table 4. Pseudo-first Order Rate Constants at Different Initial pH Values

\begin{tabular}{ccc}
\hline Initial $\mathbf{~ p H}$ & $\mathbf{k}^{\prime}\left(\mathbf{m i n}^{-1}\right)$ & $\mathbf{R}^{\mathbf{2}}$ \\
\hline 3.0 & 0.07046 & 0.8946 \\
5.0 & 0.03219 & 0.9945 \\
\hline
\end{tabular}

The best operation $\mathrm{pH}$ is noted at $\mathrm{pH} 3.0$ which gives higher COD removal than using $\mathrm{pH}$ 5.0. At higher $\mathrm{pH}(\mathrm{pH}>3.0)$, the solubility of $\mathrm{Fe}(\mathrm{III})$ ions decreased and eventually precipitated as $\mathrm{Fe}(\mathrm{OH})_{3}$ [16]. This precipitation reduces the capacity of the catalyst and thus lowering hydroxyl radical generation. Moreover, the hydroxyl radical generation, as shown in Eq. (8) below, is a reversible reaction that is very sensitive to $\mathrm{pH}$ value.

$$
\mathrm{H}_{2} \mathrm{O}_{2}+\mathrm{Fe}^{2+} \rightleftharpoons \mathrm{Fe}^{3+}+\mathrm{OH}+\mathrm{HO}^{\bullet}
$$

Based on Le Chatelier's principle, an increase in $\mathrm{pH}$ or hydroxide ions concentration may shift the equilibrium to reactants side and reduce products generation. Also, lower $\mathrm{pH}$ could remove carbonate and bicarbonate ions which are likely scavenge hydroxyl radicals in Fenton process [15].

The explanation above implies that more hydroxyl radicals are produced at $\mathrm{pH}$ 3.0. This statement is also supported the kinetic model where the pseudo-first order rate constants at $\mathrm{pH}$ 3 and 5 are calculated to be $0.07046 \mathrm{~min}^{-1}$ and $0.03219 \mathrm{~min}^{-1}$, respectively. Table 4 shows that rate constants at $\mathrm{pH} 3.0$ is about twice higher than at $\mathrm{pH}$ 5.0, since more hydroxyl radicals were produced at initial $\mathrm{pH}$ 3.0.

In this study, the $\mathrm{pH}$ in the reactor was not controlled because the $\mathrm{pH}$ of the wastewater in the feeding tank has been adjusted to the desired $\mathrm{pH}$ value. The final $\mathrm{pH}$ in the reactor after 120 min of experiment was almost similar to the initial $\mathrm{pH}$. Though Fenton process is effective at $\mathrm{pH}$ 2.0-4.0, the study at initial $\mathrm{pH}$ of 5.0 was carried out to observe whether the COD level after treatment could achieve the regulatory limit. Another consideration is an economic aspect of the wastewater $\mathrm{pH}$ adjustment back to normal prior to discharge.

The COD removal efficiency in a continuous system at initial $\mathrm{pH}$ of 3.0 and molar ratio of 1:10 was $80 \%$, while the COD removal efficiency in a batch system at the similar conditions was $88.3 \%$
[7]. Although the COD removal efficiency in a batch system is better than in a continuous system, the rate constant in a batch system $\left(0.0053 \mathrm{~min}^{-1}\right)$ is much lower than in a continuous system $\left(0.07046 \mathrm{~min}^{-1}\right)$. This is because the hydroxyl radical generation in a continuous system is more effective than in a batch system. Fenton process is more effective in a low concentrations of both organic matter and Fenton's reagent [14]. The concentrations in a batch reactor are relatively high at the initial phase when the wastewater and Fenton's reagent are fed into the reactor, while the concentrations in a continuous reactor are maintained low since the wastewater and Fenton's reagent are fed continuously into the reactor. The low concentrations in a continuous reactor may prevent the hydroxyl radical scavenging reactions, thus allowing more hydroxyl radicals are produced which caused higher rate constant in a continuous system.

\subsection{Effect of Wastewater Flow Rate}

Fig. 5 shows the effect of flow rate on COD removal. COD removal efficiency is found to decrease with increasing wastewater flow rates. This is due to lower the space time at higher wastewater flow rates in the CSTR. COD removal efficiency also increases rapidly as the reaction time increased but the rate of change of COD removal reaches plateau after steady state condition is reached.

The pseudo-first order rate constants at 30,60 and $90 \mathrm{~mL} / \mathrm{min}$ are calculated to be $0.07046 \mathrm{~min}^{-1}, 0.06442 \mathrm{~min}^{-1}, 0.06958 \mathrm{~min}^{-1}$, respectively, as shown in Table 5 .

The COD removal efficiency in previous study is higher than in this study (89.2\% in previous study vs $80 \%$ in this study) [14]. However, it is worth to note that the space time used in this study is smaller (33.33 $\mathrm{min}$ ) than the space time used in the previous study (60 $\mathrm{min}$ ) [14]. Therefore, to meet the same

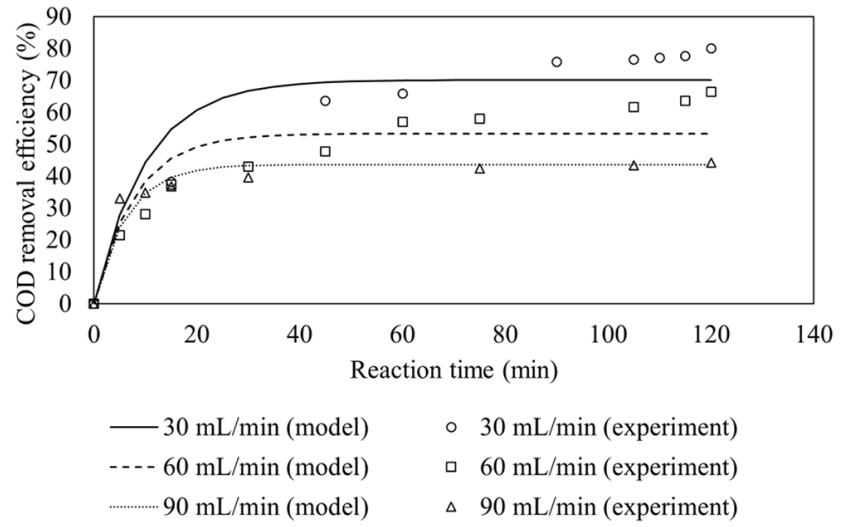

Fig. 5. Profile of COD removal at various wastewater flow rate.

Table 5. Pseudo-first Order Rate Constants at Different Wastewater Flow Rates

\begin{tabular}{ccc}
\hline Flow rate $(\mathbf{m L} / \mathbf{m i n})$ & $\mathbf{k}^{\prime}\left(\mathbf{m i n}^{-1}\right)$ & $\mathbf{R}^{2}$ \\
\hline 30 & 0.07046 & 0.8946 \\
60 & 0.06842 & 0.8409 \\
90 & 0.06958 & 0.9234 \\
\hline
\end{tabular}


COD removal efficiency, the result indicates that the reactor used for this study is smaller than the size of reactor used in previous study.

\subsection{Cost Analysis}

Operational cost is an important factor to be considered when one would like to design hybrid electrocoagulation-Fenton in a continuous system. The cost for electrocoagulation process to treat similar textile wastewater has been estimated to be IDR 81.0 per L wastewater [11]. The cost for Fenton process included the costs of chemicals and electricity. In this work, the cost for Fenton process is estimated based on two hours operation time at optimum conditions.

The chemicals used in Fenton process are hydrochloric acid to adjust initial $\mathrm{pH}$ of wastewater, ferrous sulphate heptahydrate as the source of ferrous ions, hydrogen peroxide as the source of hydroxyl radicals, and sodium hydroxide to neutralize the effluent. The amount of each chemicals used in the Fenton process and the cost are reported in Table 6 .

The total chemicals cost in Fenton process is estimated to be IDR 575.5 for two hours operation time. The electrical components of this Fenton process consist of three pumps and one stirrer. The electricity cost is calculated based on the electricity tariff in Indonesia which is IDR 1,472 per kWh. The electricity consumed in a continuous Fenton process and the cost are reported in Table 7.

The total electricity cost required for the Fenton process is IDR 874.4 for two hours operation time. The total cost of Fenton process including chemicals and electricity costs is about IDR. 1,449.9 for two hours operation. The volume used in this study is approximately $3.6 \mathrm{~L}$, hence the Fenton process operational cost is estimated to be IDR 403.0 per L wastewater. Therefore, total operational cost for yarn dyed wastewater treatment using hybrid electrocoagulation-Fenton method in continuous system is estimated to be IDR 484 per L.

In the Fenton process, the chemical cost of the continuous system (IDR 160 per L) is cheaper than the batch system (IDR 256 per L) [17], thus continuous system is more economically attractive than that in a batch system.

Table 6. Chemicals Costs Used in the Fenton Process

\begin{tabular}{cccc}
\hline Items & Quantity & Cost/unit (IDR/unit) & Cost (IDR) \\
\hline $\mathrm{HCl} 37 \%$ & $1.194 \mathrm{~mL}$ & 3.9 & 4.7 \\
$\mathrm{FeSO}_{4} \cdot 7 \mathrm{H}_{2} \mathrm{O}$ & $3.906 \mathrm{~g}$ & 1.3 & 5.1 \\
$\mathrm{H}_{2} \mathrm{O}_{2} 30 \%$ & $14.218 \mathrm{~mL}$ & 39 & 554.5 \\
$\mathrm{NaOH}$ & $1.728 \mathrm{~g}$ & 6.5 & 11.2 \\
\hline \multicolumn{5}{c}{ TOTAL } & 575.5 \\
\hline
\end{tabular}

Table 7. Electricity Cost of Fenton Process

\begin{tabular}{|c|c|c|c|c|c|}
\hline Items & Quantity & $\begin{array}{c}\text { Power } \\
\text { (W) }\end{array}$ & $\begin{array}{c}\text { Time } \\
\text { (h) }\end{array}$ & $\begin{array}{c}\text { Energy } \\
\text { (kWh) }\end{array}$ & $\begin{array}{l}\text { Cost } \\
\text { (IDR) }\end{array}$ \\
\hline Pump & 3 & 75 & 2 & 0.45 & 662.4 \\
\hline Stirrer & 1 & 72 & 2 & 0.144 & 212 \\
\hline \multicolumn{5}{|c|}{ TOTAL } & 874.4 \\
\hline
\end{tabular}

\section{Conclusions}

The results in this study indicates that hybrid electrocoagulation-Fenton method in a continuous mode can be as a reliable process to treat yarn dyed wastewater for large scale application. The optimum conditions of Fenton process in a CSTR can be reached when Fe(II) catalysts are fed both into both the feed tank and the reactor at the initial condition. The best parameters used in this study are: $\mathrm{Fe}(\mathrm{II}) / \mathrm{H}_{2} \mathrm{O}_{2}$ molar ratio of 1:10 in the feed stream, initial wastewater $\mathrm{pH}$ of 3.0, and wastewater flow rate of $30 \mathrm{~mL} / \mathrm{min}$. The COD removal efficiency in Fenton process can reach $80 \%$ under the optimum condition. Moreover, COD removal using Fenton process can also be fitted to the CSTR model for pseudo-first order kinetic with the rate constant (k') of $0.07046 \mathrm{~min}^{-1}$ at the optimum condition with $\mathrm{R}^{2}=0.8946$. The estimated operational cost for the yarn dyed wastewater treatment using hybrid electrocoagulation-Fenton in the continuous system is IDR 484 per L wastewater. The chemical cost used in continuous system was IDR 160/L which is cheaper than in a batch system (IDR 256/L).

\section{Acknowledgments}

The authors would like to acknowledge the financial support by PUPT 2016 grant form Directorate General for Higher Education and Research, Indonesia. The authors also thank Dr. Tuti Lim for her help.

\section{References}

1. Ratna, Padhi BS. Pollution due to synthetic dyes toxicity \& carcinogenicity studies and remediation. Int. J. Environ. Sci. 2012;3:940-955.

2. Nawaz MS, Ahsan M. Comparison of physico-chemical, advanced oxidation and biological techniques for the textile wastewater treatment. Alexandria Eng. J. 2014;53:717-722.

3. Morali EK, Uzal N, Yetis U. Ozonation pre and post-treatment of denim textile mill effluents: Effect of cleaner production measures. J. Clean Prod. 2016;137:1-9.

4. Sreeja PH, Sosamony KJ. A comparative study of homogeneous and heterogeneous photo-Fenton process for textile wastewater treatment. Procedia Technol. 2016;24:217-223.

5. Youssef NA, Shaban SA, Ibrahim FA, Mahmoud AS. Degradation of methyl orange using Fenton catalytic reaction. Egypt. J. Petrol. 2016;25:317-321.

6. Wang N, Zheng T, Zhang G, Wang P. A review on Fenton-like processes for organic wastewater treatment. J. Environ. Chem. Eng. 2016;4:762-787.

7. Riadi L, Sapei L, Lidiawati T, Agustin YE. Application of a hybrid electrocoagulation-Fenton process in yarn dyed wastewater: Kinetic study. IOP Conf. Ser. Mater. Sci. Eng. 2017;162:012026.

8. Guclu D, Sirin N, Sahinkaya S, Sevimli MF. Advanced treatment of coking wastewater by conventional and modified 
Fenton processes. Environ. Prog. Sustain. Energy 2011;32: 176-180.

9. Wang Z, Chen K, Li J, Mo L, Wang Q. The removal of COD from bleaching effluents by Fenton's reagent: Effect of system parameters and kinetic study. Environ. Prog. Sustain. Energy 2011;30:168-176.

10. Lucas MS, Peres JA. Removal of COD from olive mill wastewater by Fenton's reagent: Kinetic study. J. Hazard. Mater. 2009;168:1253-1259.

11. Riadi L, Ferydhiawati W, Loeman LDS. Pengolahan primer limbah tekstil dengan elektrokoagulasi dan analisa biaya operasi. Reaktor 2014;15:73-78.

12. APHA. Standard methods for the examination of water and wastewater. 20th ed. Washington D.C.: American Public Health Association; 1998.

13. Karatas M, Argun ME. Decolorization of antraquinonic dye, Reactive Blue 114 from synthetic wastewater by Fenton process: Kinetics and thermodynamics. J. Ind. Eng. Chem.
2012;18:1058-1062.

14. Zhang H, Choi HJ, Huang CP. Treatment of landfill leachate by Fenton's reagent in a continuous stirred tank reactor. $J$. Hazard. Mater. 2006;B136:618-623.

15. Argun ME, Karatas M. Application of Fenton process for decolorization of reactive black 5 from synthetic wastewater: Kinetics and thermodynamics. Environ. Prog. Sustain. Energy 2011;30:540-548

16. Fassi S, Djebbar K, Bousnoubra I, Chenini H, Sehili T. Oxidation of bromocresol green by different advanced oxidation processes: Fenton, Fenton-like, photo-Fenton, photo-Fenton-like, and solar light: Comparative study. Desalin. Water Treat. 2014;52:4982-4989.

17. Riadi L, Wisanto R, Herlambang AR, Vania SM, Widyasayogo A. A comparative study of yarn dyed wastewater using Fenton's reagent and ozonation: Removal efficiency and economic analysis. Reaktor 2016;16:207-211. 